OPEN ACCESS

Edited by:

Jean-Marc Sabatier,

Aix-Marseille Université, France

Reviewed by: Nathalie K. Zgheib, American University of Beirut, Lebanon Wojciech Francuzik, Charité-Universitätsmedizin Berlin,

Germany

*Correspondence: Chang-Gue Son ckson@dju.ac.kr

Specialty section: This article was submitted to Translational Pharmacology, a section of the journal Frontiers in Pharmacology

Received: 25 March 2020 Accepted: 11 September 2020 Published: 07 October 2020

Citation: Lee E-J, Ahn Y-C, Kim Y-I, Oh M-S, Park Y-C and Son C-G (2020) Incidence Rate of Hypersensitivity Reactions to Bee-Venom Acupuncture. Front. Pharmacol. 11:545555. doi: 10.3389/fphar.2020.545555

\section{Incidence Rate of Hypersensitivity Reactions to Bee-Venom Acupuncture}

\author{
Eun-Jung Lee ${ }^{1}$, Yo-Chan Ahn ${ }^{2}$, Young-II Kim ${ }^{3}$, Min-Seok Oh ${ }^{1}$, Yang-Chun Park ${ }^{4}$ \\ and Chang-Gue Son ${ }^{5 *}$ \\ ${ }^{1}$ Department of Korean Rehabilitation Medicine, College of Korean Medicine, Daejeon University, Daejeon, South Korea, \\ 2 Department of Health Service Management, Daejeon University, Daejeon, South Korea, ${ }^{3}$ Department of Acupuncture and \\ Moxibustion Medicine, College of Korean Medicine, Daejeon University, Daejeon, South Korea, ${ }^{4}$ Division of Respiratory \\ System, Department of Internal Medicine, College of Korean Medicine, Daejeon University, Daejeon, South Korea, \\ ${ }^{5}$ Department of Gastrobilliary System, Dunsan Hospital of Daejeon University, Daejeon, South Korea
}

Introduction: Bee-venom acupuncture (BVA) has been widely applied to various disorders including pain-related diseases; however, patients are often warned of adverse reactions such as anaphylaxis. This study aimed to estimate the risk of hypersensitivity reactions to BVA and to determine their clinical features.

Methods: We retrospectively surveyed the medical records of patients treated by BVA between January 2010 and April 2019 in Dunsan Hospital of Daejeon University, and all cases of allergic reactions and their clinical symptoms were analyzed.

Results: A total of 8,580 patients (males 4,081 and females 4,499) were treated with BVA which amounts to a total of 60,654 treatments (average 7.1 \pm 14.8 times). A total of fifteen patients ( 7 males and 8 females) reported an allergic reaction $(0.175 \%, 95 \% \mathrm{Cl}, 0.086-$ 0.263) of type 1 hypersensitivity, indicating a rate of allergic reaction in $0.025 \%(95 \% \mathrm{Cl}$, 0.012-0.037) of the total BVA treatments. The average number of BVA treatments in those patients was $6.9 \pm 6.5$ (males: $4.1 \pm 3.4$ and females: $9.3 \pm 7.9$ ). Among the cases of hypersensitivity reactions, 4 involved anaphylactic shock; therefore, the incidence rate of anaphylaxis was $0.047 \%(95 \% \mathrm{Cl}, 0.001-0.092)$ for the 8,580 subjects and $0.007 \%$ $(95 \% \mathrm{Cl}, 0.000-0.013)$ for the 60,654 treatments. All grade 1 cases were recovered within 1 day, whereas others took up to 30 days for complete recovery.

Conclusion: Our results may emphasize paying attention to unforeseeable risks of anaphylaxis after bee-venom acupuncture. This study could be essential reference data for the guidelines of appropriate use of bee-venom acupuncture and bee-venom-derived interventions in clinical applications.

Keywords: bee venom, adverse drug reaction, hypersensitivity, anaphylaxis, side effect, acupuncture 


\section{INTRODUCTION}

Recently, venoms have received a lot of attention as an intervention for diseases. Among these, bee-venom is most commonly used as painkillers and anti-inflammatory drugs (Seo et al., 2017; Memariani et al., 2019). Furthermore, beevenom is an effective therapeutic for other challenging disorders, including incurable skin disease, cancer, and Parkinson's disease (Hartmann et al., 2016; Gu et al., 2018; Aufschnaiter et al., 2020). Despite these potential applications, however, the clinical use of bee-venom is limited due to allergic reactions, including lifethreatening responses such as anaphylaxis.

In general, adverse drug reactions (ADRs) are one of the major reasons why the drugs were withdrawn from the post marketing phase (Demoly et al., 2008; Onakpoya et al., 2019). Drug hypersensitivity reactions account for $15 \%$ of ADRs (Pichler and Hausmann, 2016). Drug-induced anaphylaxis is the most serious and life-threatening hypersensitivity reaction (Turner et al., 2017) and many drugs that trigger anaphylaxis involving antibiotics, radiocontrast agents, and nonsteroidal anti-inflammatory drugs (NSAIDs) are frequently problematic in clinic (Wood et al., 2014; Giavina-Bianchi et al., 2018). Regarding NSAIDs-related incidence rate of hypersensitivity and anaphylaxis, one US clinical study reported as 0.30 and $0.02 \%$, respectively (Blumenthal et al., 2017). Another study presented incidence rates of $0.48 \%$ for hypersensitivity reactions and $0.01 \%$ for anaphylaxis from 9,528 MRI examinations with contrast-agent (Li et al., 2006).

Bee-venom acupuncture (BVA) is a common therapeutic used worldwide, especially in Korean and Chinese clinics. Since one death by BVA anaphylactic shock was reported, the safety of bee-venom has been an important issue in Korea (Jung et al., 2012b). Two studies demonstrated partially BVA-related hypersensitivity reactions using data from clinical trials or hospital records (Park et al., 2015; Kim et al., 2016); however, further studies are still required to provide better clinical guidance for safe use of BVA. The present study aimed to estimate the risk size of hypersensitivity reactions by BVA and to determine their clinical features.

\section{MATERIALS AND METHODS}

\section{Study Design}

This study was a retrospective analysis. The data source was the electronic medical records (EMRs) of 66,614 subjects who had visited the pain-spine center and rehabilitation center in Dunsan Hospital of Daejeon University, South Korea, from January 2010 to March 2019. This process was conducted via integrated hospital information system (IHIS) that analyzed the order communication system (OCS) and EMR. We first selected only subjects treated with BVA and then searched the cases with hypersensitivity after BVA treatment. We analyzed the incidence rate of hypersensitivity

Abbreviations: ADR, Adverse drug reaction; BVA, Bee-venom acupuncture; EMR, Electronic medical record; ICD-10; International classification of diseases10, NSAID, Nonsteroidal anti-inflammatory drug. reactions and anaphylactic shock along with their clinical features. The inclusion criteria for the selection of patients and the incidence of a hypersensitivity reaction were as follows: 1 ) subjects who had been treated with BVA at least once, as recorded in their EMRs; or 2) subjects who complained of a BVA-related systemic allergic reaction with/without the prescription of anti-allergic drugs such as antihistamines, adrenaline, or adrenal cortex hormones. Strategy to identify the hypersensitivity cases was based on the guideline for BVA treatment, which all the cases of BVA allergic reaction should be referred to one conventional doctor in same hospital. We carefully reviewed the full medical records for all the suspected cases.

\section{BVA}

The bee-venom source for BVA used in two centers was produced by Green Myeongpum Pharm Company (Namyangju, Korea). This bee-venom source was validated for its main active compound (over 99.9\% melittin) and allergen-free purification (phospholipase A2, apamin, hyaluronidase, and histamine) and was then diluted to $10 \%$ with normal saline by Jaseng Namyangju Industrial Institute (Namyangju, Korea) or Kirin Korean Medicine Industrial Institute (Wonju, Korea). BVA treatment was conducted with an injection of bee-venom solution (range, 1.0 to $2.0 \mathrm{~mL}$ ) at a specific acupoint of skin or muscle with interval of 3 or 4 days.

\section{Ethics Statement}

This study was approved by the Institutional Review Board for Human Research of Daejeon University Dunsan Hospital (approval number: DJDSKH-18-E-08-2). We have obtained verbal consent from every subject identified as having a hypersensitivity reaction.

\section{Data Source Extraction and Analysis}

We extracted general information on the subjects treated with BVA including gender, age, frequency of BVA prescriptions and the main health complaint (according to the International Classification of Diseases-10; ICD 10) and cases of hypersensitivity reaction including its primary symptoms, the recovery period, and the presence of a family history of allergy-related illness. We, thus, calculated the incidence rate of hypersensitivity reactions and anaphylactic shock, with the number of subjects and times of BVA treatment. The type of hypersensitivity reaction was classified according to immune mechanisms and clinical symptoms (Dispenza, 2019). The severity of the allergic symptoms was assessed in three categories proposed by Brown SG (Brown, 2004), which was established by slight modification from Muller's four classifications (Mueller, 1966), while the definition of anaphylaxis followed the 2010 World Allergy Organization guideline (Simons et al., 2011) as shown in Supplementary Table 1. For every subject identified as having a hypersensitivity reaction, we conducted a telephone survey to clarify the consequences and other medical events since they stopped BVA treatment.

\section{Statistical Analysis}

Categorical variables were expressed as frequency and percentages, and averages were expressed as the means \pm standard deviation 
(SD). The incidence rate was given as a percentage within the $95 \%$ confidence interval. The comparison between male and female was analyzed using chi-squared test or Fisher exact test. Statistical analyses were performed with the SPSS statistical software package version 18.0 (SPSS Inc., Chicago, IL, USA).

\section{RESULTS}

\section{Characteristics of Subjects}

From EMR analysis, 8,580 subjects (4,081 males and 4,499 females) met our study criteria. The total number of BVA prescriptions was 60,654, accounting for an average of $7.1 \pm$ 14.8 BVA treatments per subject (males: $7.0 \pm 11.8$ vs. females: $7.1 \pm 17.1, \mathrm{p}>0.05)$. The median age of the subjects was 53 years (range, 13-98 years). Most subjects (93\%) had complaints of the musculoskeletal system and connective tissue or injury-related pain. The number of subjects were counted without duplication, no matter how many times they visited hospitals as an inpatient or outpatient (Table 1).

\section{Incidence Rates of Hypersensitivity Reaction and Anaphylaxis}

Fifteen subjects (seven males and eight females) showed hypersensitivity reactions to BVA, with an incidence rate of $0.175 \%$ (95\% CI: $0.086-0.263 \%$ ) from 8,580 subjects and $0.025 \%$ (95\% CI: 0.012-0.037\%) from 60,654 treatments. Among those, four cases were anaphylactic shock, corresponding to $0.047 \%$ (95\% CI: $0.001-0.092)$ of subjects and $0.007 \%$ (95\% CI: $0.000-$ 0.013 ) of treatments, respectively. No significant difference by gender was observed for total hypersensitivity. The anaphylactic shock was more frequent in female than male for both subjects $(0.067 \%$ in female vs. $0.025 \%$ in male) and treatments $(0.003 \%$ in female vs. $0.009 \%$ in male), but no statistical significance was observed ( $\mathrm{p}>0.05$, Table 2).

TABLE 1 | Characteristics of subjects.

\begin{tabular}{|c|c|c|}
\hline Subjects & Male/Female (\%) & Total \\
\hline Number of subjects (\%) & 4,081 (47.6)/4,499 (52.4) & $8,580(100)$ \\
\hline Median age (year, range) & 49 (13 to 88$) / 53$ (13 to 98$)$ & 53 (13 to 98$)$ \\
\hline $\begin{array}{l}\text { Number of BVA treatments } \\
\text { (\%) }\end{array}$ & $\begin{array}{c}28,626(47.6) / 32,028 \\
(52.4)\end{array}$ & $60,654(100)$ \\
\hline Mean N. of BVA treatments & $7.0 \pm 11.8 / 7.1 \pm 17.1$ & $7.1 \pm 14.8$ \\
\hline \multicolumn{2}{|l|}{ Main complains (ICD-10) } & $\begin{array}{l}\text { N. of subjects } \\
(\%)\end{array}$ \\
\hline \multicolumn{2}{|c|}{$\begin{array}{l}\text { M00-M99: Diseases of the musculoskeletal system and } \\
\text { connective tissue }\end{array}$} & $4,724(50.2)$ \\
\hline \multicolumn{2}{|c|}{$\begin{array}{l}\text { SO0-T98: Injury, poisoning and certain other consequences } \\
\text { of external causes }\end{array}$} & $4,027(42.8)$ \\
\hline \multicolumn{2}{|c|}{ G00-G99: Diseases of the nervous system } & $449(4.8)$ \\
\hline \multicolumn{2}{|c|}{$\begin{array}{l}\text { R00-R99: Symptoms, signs and abnormal clinical and } \\
\text { laboratory findings, NEC }\end{array}$} & $95(1.0)$ \\
\hline \multicolumn{2}{|c|}{ Others } & $110(1.8)$ \\
\hline \multicolumn{2}{|l|}{ Total subjects* } & $9,405(100)$ \\
\hline
\end{tabular}

*Duplication was permitted to be counted in case one patient received BVA treatment as an inpatient and an outpatient. Therefore, this number is larger than number for analysis (8,580 subjects).

\section{Clinical Features of Hypersensitivity Reaction and Anaphylaxis}

Regarding the severity of the symptom, 6 cases were grade 1 , while 7 and 2 cases were belonged to grade 2 and 3, respectively (Table 2). All cases of hypersensitivities appeared immediately or within one hour after BVA treatment, which is the typical feature of type 1 hypersensitivity. They completely recovered, although one subject was hospitalized. Skin symptoms such as generalized itchiness and urticaria were the most common (80\%), followed by respiratory symptoms $(46.7 \%)$, cardiovascular and neurological symptoms (26.7\%), and gastrointestinal symptoms (20\%). Twelve out of 15 cases occurred after several BVA treatments, while three cases showed the hypersensitivity reactions on the first exposure in our hospital (Table 3).

\section{DISCUSSION}

In this study, we investigated the clinical question: what is the risk size of BVA-derived hypersensitivity reactions, including anaphylactic shock and its clinical features. Most of the subjects had disorders related to the musculoskeletal system and joints, on which bee-venom and its main components may have a therapeutic effect as a painkiller or chondroprotective agent (Jeong et al., 2015). The incidence rate of hypersensitivity reactions in our study $(0.175 \%$ from 8,580 subjects and $0.025 \%$ from 60,654 treatments) was slightly lower than results from another retrospective study, which showed a $0.23 \%$ incidence rate of BVA-induced hypersensitivity reactions (Kim et al., 2016). Drug-induced hypersensitivities can be broadly classified into four types by immune mechanisms (Dispenza, 2019). BV-induced allergic reaction is known mainly to be of type 1 hypersensitivity which is mediated by IgE (Kwon et al., 2009).

In our results, all cases with hypersensitivities appeared immediately or within one hour after BVA treatment,

TABLE 2 | Incidence rate of hypersensitivity reaction and anaphylactic shock.

\begin{tabular}{lc}
\hline Hypersensitivity reaction & Incidence rate (95\% Cl) \\
\hline By subjects $(15$ of 8,580$)$ & $0.175 \%(0.086-0.263)$ \\
Male $(7$ of 4,081$)$ & $0.172 \%(0.045-0.298)$ \\
Female $(8$ of 4,499$)$ & $0.178 \%(0.055-0.301)$ \\
By treatments $(15$ of 60,654$)$ & $0.025 \%(0.012-0.037)$ \\
Male $(7$ of 28,626$)$ & $0.024 \%(0.006-0.043)$ \\
Female $(8$ of 32,028$)$ & $0.025 \%(0.008-0.042)$ \\
\hline Anaphylaxis shock & Incidence rate (95\% Cl) \\
\hline By subjects $(4$ of 8,580$)$ & $0.047 \%(0.001-0.092)$ \\
Male $(1$ of 4,081$)$ & $0.025 \%(-0.024-0.073)$ \\
Female $(3$ of 4,49 & $0.067 \%(-0.009-0.142)$ \\
By treatments $(4$ of 60,654$)$ & $0.007 \%(0.000-0.013)$ \\
Male $(1$ of 28,626$)$ & $0.003 \%(-0.003-0.010)$ \\
Female $(3$ of 32,028$)$ & $0.009 \%(-0.001-0.020)$ \\
\hline Severity of symptom & Frequency (\%)
\end{tabular}

Grade 1 (Mild)

Grade 2 (Moderate)

Grade 3 (Severe)
6 (male 4, female 2), $40.0 \%$

7 (male 3, female 4), $46.7 \%$

2 (male 0, female 2), $13.3 \%$ 
TABLE 3 | Characteristics of 15 allergic reaction cases with bee-venom acupuncture.

\begin{tabular}{|c|c|c|c|c|c|c|}
\hline \multirow{2}{*}{$\begin{array}{l}\text { Case } \\
\text { (sex/age) }\end{array}$} & \multirow{2}{*}{$\begin{array}{l}\text { Chief complaints } \\
\text { (allergy } \\
\text { disorders }^{\star} \text { ) }\end{array}$} & \multirow{2}{*}{$\begin{array}{l}\text { Family } \\
\text { history of } \\
\text { allergy }\end{array}$} & \multirow{2}{*}{$\begin{array}{l}\text { No. BVA } \\
\text { treatment }^{\dagger} \\
\left.\text { (Interval }^{\ddagger}\right)\end{array}$} & \multicolumn{3}{|l|}{ Allergic reaction } \\
\hline & & & & Main symptoms & $\begin{array}{c}\text { Type } \\
\text { (Grade) }^{\S}\end{array}$ & Outcome (follow-up) \\
\hline $\begin{array}{l}\mathrm{P} 1 \\
(\mathrm{M} / 36)\end{array}$ & Cervical sprain & $\begin{array}{l}\text { Fish allergy } \\
\text { (mother) }\end{array}$ & $1(0 \mathrm{~d})$ & Urticaria & $\begin{array}{l}\text { Type1 } \\
\text { (G 1) }\end{array}$ & $\begin{array}{l}\text { Recovered } \\
\text { (1d, itch) }\end{array}$ \\
\hline $\begin{array}{l}\mathrm{P} 2 \\
(\mathrm{M} / 38)\end{array}$ & Cervical sprain & None & $2(14 d)$ & Urticaria & $\begin{array}{l}\text { Type1 } \\
\text { (G 1) }\end{array}$ & $\begin{array}{l}\text { Recovered } \\
\text { (1d, itch) }\end{array}$ \\
\hline $\begin{array}{l}\mathrm{P3} \\
(\mathrm{M} / 44)\end{array}$ & Cervical sprain & $\begin{array}{l}\text { Asthma } \\
\text { (brother) }\end{array}$ & $4(3 d)$ & Urticaria & $\begin{array}{l}\text { Type1 } \\
\text { (G 1) }\end{array}$ & $\begin{array}{l}\text { Recovered } \\
\text { (1d, itch) }\end{array}$ \\
\hline $\begin{array}{l}\mathrm{P} 4 \\
(\mathrm{M} / 48)\end{array}$ & Lumbar HNP & None & $3(7 d)$ & Urticaria & $\begin{array}{l}\text { Type1 } \\
\text { (G 1) }\end{array}$ & $\begin{array}{c}\text { Recovered } \\
\text { (1d, itch) }\end{array}$ \\
\hline $\begin{array}{l}P 5 \\
(F / 53)\end{array}$ & $\begin{array}{l}\text { Cervical HNP } \\
\text { (aspirin allergy) }\end{array}$ & None & $1(0 \mathrm{~d})$ & Urticaria & $\begin{array}{l}\text { Type1 } \\
\text { (G 1) }\end{array}$ & $\begin{array}{l}\text { Recovered } \\
\text { (1 d, itch) }\end{array}$ \\
\hline $\begin{array}{l}\mathrm{P} 6 \\
(\mathrm{~F} / 56)\end{array}$ & Cervical sprain & None & $1(0 \mathrm{~d})$ & Urticaria & $\begin{array}{l}\text { Type1 } \\
\text { (G 1) }\end{array}$ & $\begin{array}{l}\text { Recovered } \\
\text { (1 d, itch) }\end{array}$ \\
\hline $\begin{array}{l}\mathrm{P7} \\
(\mathrm{M} / 32)\end{array}$ & $\begin{array}{l}\text { Knee contusion } \\
\text { (allergic rhinitis) }\end{array}$ & $\begin{array}{l}\text { Allergic } \\
\text { rhinitis } \\
\text { (brother) }\end{array}$ & $2(8 d)$ & $\begin{array}{l}\text { Dizziness, throat tightness, } \\
\text { weakness, anxiety }\end{array}$ & $\begin{array}{l}\text { Type1 } \\
\text { (G 2) }\end{array}$ & $\begin{array}{c}\text { Recovered } \\
\text { (1d, dizziness) }\end{array}$ \\
\hline $\begin{array}{l}\mathrm{P} 8 \\
(\mathrm{M} / 64)\end{array}$ & Sprain of knee & None & $11(22 d)$ & $\begin{array}{l}\text { Urticaria, constriction in chest, } \\
\text { weakness }\end{array}$ & $\begin{array}{l}\text { Type1 } \\
\text { (G 2) }\end{array}$ & $\begin{array}{c}\text { Recovered } \\
\text { (30 d, weakness) }\end{array}$ \\
\hline $\begin{array}{l}\mathrm{P9} \\
(\mathrm{F} / 32)\end{array}$ & Cervical sprain & None & $14(64 d)$ & $\begin{array}{l}\text { Urticaria, localized edema, } \\
\text { throat tightness }\end{array}$ & $\begin{array}{l}\text { Type1 } \\
\text { (G 2) }\end{array}$ & $\begin{array}{l}\text { Recovered } \\
\text { (2 d, itch) }\end{array}$ \\
\hline $\begin{array}{l}\mathrm{P} 10 \\
(\mathrm{~F} / 42)\end{array}$ & $\begin{array}{l}\text { Cervical sprain } \\
\text { (allergic rhinitis) }\end{array}$ & None & $22(7 \mathrm{~d})$ & $\begin{array}{l}\text { Headache, dizziness, numbness, } \\
\text { abdominal pain, generalized pain }\end{array}$ & $\begin{array}{l}\text { Type1 } \\
\text { (G 2) }\end{array}$ & $\begin{array}{l}\text { Recovered } \\
\text { (21 d, dizziness) }\end{array}$ \\
\hline $\begin{array}{l}\mathrm{P} 11 \\
(\mathrm{~F} / 42)\end{array}$ & $\begin{array}{l}\text { Frozen shoulder } \\
\text { (contrast agent } \\
\text { allergy) }\end{array}$ & None & $15(4 d)$ & $\begin{array}{l}\text { Urticaria, erythema, throat } \\
\text { swelling }\end{array}$ & $\begin{array}{l}\text { Type1 } \\
\text { (G 2) }\end{array}$ & $\begin{array}{l}\text { Recovered } \\
\text { (3 d, throat swelling) }\end{array}$ \\
\hline $\begin{array}{l}\mathrm{P} 12 \\
(\mathrm{M} / 70)\end{array}$ & $\begin{array}{l}\text { Lumbar stenosis } \\
\text { (asthma) }\end{array}$ & None & $6(362 d)$ & $\begin{array}{l}\text { Urticaria, pain, chilling, cold sweat, nausea, vomiting, } \\
\text { anxiety, dyspnea }\end{array}$ & $\begin{array}{l}\text { Type1 } \\
\text { (G 2) }\end{array}$ & $\begin{array}{c}\text { Recovered } \\
\text { (30 d, anxiety) }\end{array}$ \\
\hline $\begin{array}{l}\mathrm{P} 13 \\
(\mathrm{~F} / 62)\end{array}$ & Lumbar HNP & None & $13(231 d)$ & $\begin{array}{l}\text { Urticaria, paresthesia, } \\
\text { throat tightness, dyspnea }\end{array}$ & $\begin{array}{l}\text { Type1 } \\
\text { (G 2) }\end{array}$ & $\begin{array}{l}\text { Recovered } \\
\text { (2 d, weakness) }\end{array}$ \\
\hline $\begin{array}{l}\mathrm{P} 14 \\
(\mathrm{~F} / 59)\end{array}$ & Spinal stenosis & None & $2(391 d)$ & $\begin{array}{l}\text { Urticaria, throat tightness, chest pain, nausea, vomiting, } \\
\text { dizziness, dyspnea, hypotension, loss of consciousness }\end{array}$ & $\begin{array}{l}\text { Type1 } \\
\text { (G 3) }\end{array}$ & $\begin{array}{l}\text { Recovered } \\
\text { (14 d, dizziness, } \\
\text { weakness) }\end{array}$ \\
\hline $\begin{array}{l}\text { P15 } \\
(F / 60)\end{array}$ & $\begin{array}{l}\text { Cervical HNP } \\
\text { (allergic rhinitis) }\end{array}$ & $\begin{array}{l}\text { Allergic } \\
\text { rhinitis } \\
\text { (son) }\end{array}$ & $6(129 d)$ & $\begin{array}{l}\text { Weakness, paresthesia, throat tightness, dyspnea, lip } \\
\text { edema, hypotension, } \\
\text { loss of consciousness }\end{array}$ & $\begin{array}{l}\text { Type1 } \\
\text { (G 3) }\end{array}$ & $\begin{array}{c}\text { Recovered } \\
\text { (3 d, lip edema) }\end{array}$ \\
\hline
\end{tabular}

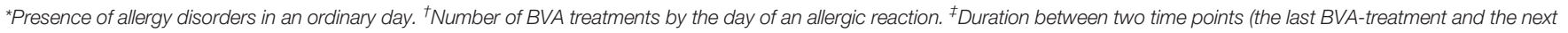

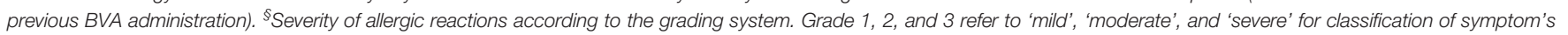
severity. "The time point when the last symptom(s) disappeared.

indicating the typical feature of type 1 hypersensitivity. Their clinical severities were $40.0 \%, 46.7 \%$, and $13.3 \%$ for grade 1 to grade 3, respectively (Table 2 ). In general, anaphylaxis is the most severe systemic hypersensitivity reaction. In the United States, $1.6-5.1 \%$ of the population are estimated to have experienced anaphylaxis, and $1 \%$ of hospitalizations for anaphylaxis showed fatal results (Ma et al., 2014; Wood et al., 2014). The contrast agents for MRI examination are well known to show a high rate of anaphylactic reactions. Our data showed four cases of anaphylaxis due to BVA, corresponding to $0.047 \%$ of subjects and $0.007 \%$ of treatments (Table 2), which is very similar to the overall incidence rates of MRI contrast agents. One Korean group analyzed MRI contrast agent-related adverse reactions according to both patients (84,367 patients) and doses (141,623 total doses) as we did, presenting $0.121 \%$ (patients) and $0.079 \%$ (doses) for hypersensitivity and $0.01 \%$ (patients) and $0.008 \%$ (doses) for anaphylaxis (Jung et al, 2012a). Although our study and other studies showed the two kinds of the incidence rate of hypersensitivity reactions and anaphylaxis (patients vs. treatments), treatment-derived rates would be underestimated due to the repeated BVA treatments likely 5 to 10 BVA sessions per patient. Accordingly, we have to notice that the patient-derived rates reflect further practically the risk sizes comparing with the treatment-derived rates.

In general, the occurrence of drug-related adverse reactions, including anaphylaxis, depends on the three main factors: the drug properties themselves, the genetic backgrounds of subjects and environmental factors such as the coadministration of drugs, alcohol or food, underlying disorders, gender, age, or even psychiatric status (Merle et al., 2005; Nguyen et al., 2006; Zhang et al., 2009; Liao et al., 2019). In its original state, bee venom is a complex mixture of proteins (phospholipase A2, phospholipase B, and hyaluronidase), peptides (mainly melittin) and low-molecular-mass components such as histamine (Wehbe et al., 2019), while the bee-venom which was used in this study is composed of $99.9 \%$ melittin with removal of major toxic/allergic proteins. One previous study in Korea (using a diluted BV material without allergen-purification studied from 1998 to 
2000) presented a 4-fold higher anaphylaxis incidence rate ( $0.03 \%$ of 32,000 treatments) compared to the present results (Hwang and Lee, 2000). Females are known to be more susceptible to ADRs, including anaphylaxis (Jensen-Jarolim and Untersmayr, 2008). In our results, the incidence rate of anaphylaxis (but not total hypersensitivity) was 3-fold higher in females than in males, as shown in the above MRI contrast agents (1.5-fold) (Jung et al., 2012a) and BVA (2.4-fold in Kim's study, 2.7-fold in Hwang's study) (Hwang and Lee, 2000; Kim et al., 2016). Previous clinical studies have reported a positive relationship between immune disorders and hypersensitivity reactions, likely a 1.7 -fold higher incidence of adverse reactions to NSAIDs in subjects with autoimmune diseases (Blumenthal et al., 2017). Our study found that $40 \%$ of cases ( 6 out of 15 with hypersensitivity reactions) had underlying allergic diseases, but we cannot identify the exact correlation due to the lack of information for all subjects underwent BVA treatment. As in other studies, age did not affect the incidence of hypersensitivity or anaphylactic reactions in our study. Regarding the main symptoms of hypersensitivity reactions and their frequency, skin symptoms such as generalized itchiness and urticaria were the most common (12 cases, $80 \%$ ) and disappeared within one or two days.

The subjects with a higher grade of severity (2 or 3 grade) complained of respiratory, gastrointestinal, cardiovascular, and neurological symptoms such as dyspnea, nausea, vomiting, abdominal pain, hypotension, or loss of consciousness, respectively. Although one patient was hospitalized for three days, and weakness and anxiety in two subjects were likely to last up to 30 days, all patients completely recovered (Table 3). The two severe cases with hypotension and loss of consciousness were treated with epinephrine and dexamethasone, while 13 cases (mild and moderate) were treated with antihistamine only or as a combination with dexamethasone according to international management guidelines for anaphylaxis. The average number of BVA treatments was $7.1 \pm 14.8$ in a total 8,580 subjects (Table 1), and 15 cases had the $6.9 \pm 6.5$ treatments (males $4.1 \pm 3.4$ and females $9.3 \pm 7.9$ ) before occurrence of the adverse reactions (Table 3, but the average number of treatments was not shown in table). Twelve cases of hypersensitivity reactions happened after several BVA treatments, while three cases showed it immediately on the first exposure in our hospital. However, these three subjects (P1, P5 and P6 in Table 3) had had BVA treatments in other clinics before visiting our hospital and two (P1 and P6) had experiences of mild allergic reactions (reconfirmed by phone call). In general, anaphylaxis is caused by IgE-mediated immunological release of chemical mediators; thus, repeated exposure to allergens can boost the production of IgE (Okano et al., 1999). One study reported that half of the beevenom anaphylaxis-related deaths did not show allergic reactions to bee-venom exposure in the past (Golden, 2007). Interestingly, all anaphylaxis cases had long duration (between 129 391 days) between two time points, the last BVA treatment and the next previous BVA administration (Table 3). Currently, we cannot explain the reasons for our results; however, we have to pay attention to melittin itself, the core component of BV. Although the bee-venom used in present study was prepared by removing major allergens, melittin was known to induce minor allergic reaction (Jarisch et al., 1979). Melittin also can form a complex with phospholipase A2 (PLA2, the second most abundant compound), which consequentially cleaves cellular membrane phospholipids and then leads to inflammatory reaction (Mingarro et al., 1995). Accordingly, the repeated exposure of melittin of BVA could evoke the allergic reactions including anaphylactic shock in certain subjects. This might be supported by our result, which high grades (2 or 3 ) of hypersensitivity reactions occurred with greater number of BVA treatments $(10.1 \pm 6.7$ times) compared to grade 1 ( $2.0 \pm 1.3$ times $)$.

Skin tests are generally adapted for the prediction of a drug hypersensitivity (Brockow et al., 2002). At present, we recommend skin tests for every patient requiring $\mathrm{BVA}$ treatment, one before the first treatment and another after the 2-week interval period. However, it should be noted that all hypersensitive persons cannot be identified only through the skin test. High levels of serum IgE and tryptase are good indicators for type 1 hypersensitivity, including anaphylaxis (Rueff et al., 2009). In addition, the determination of the baseline serum tryptase levels in patients who underwent anaphylaxis to BVA could be helpful to rule out an unspecific mast cell activation disorder (Vitte, 2015). We however didn't conduct those tests in present study. This would be the limitation of our present study along with a retrospective study.

Taken together, we can expect that the BVA-related risks of a hypersensitivity reaction and anaphylaxis are approximately 0.175 and $0.025 \%$ of subjects, and 0.025 and $0.007 \%$ of treatments. This risk of anaphylaxis shouldn't be ignored, moreover requires to pay careful attention in clinical application of BVA due to the possibility of fatal outcome. This study would be a useful reference for the safe clinical application of bee-venomderived interventions and their pharmaceutical development in the future.

\section{DATA AVAILABILITY STATEMENT}

The raw data supporting the conclusions of this article will be made available by the authors, without undue reservation, to any qualified researcher.

\section{ETHICS STATEMENT}

The studies involving human participants were reviewed and approved by Institutional Review Board for Human Research in Dunsan Hospital of Daejeon University (approval number: DJDSKH-18-E-08-2). Written informed consent for participation was not provided by the participants' legal guardians/next of kin because the institute proved the no- 
requirement of the written consent; however, we have obtained verbal consent from every subject identified as having a hypersensitivity reaction.

\section{AUTHOR CONTRIBUTIONS}

E-JL participated mainly in the design of the experiments and manuscript preparation. Y-CA, Y-CP, M-SO, and Y-IK contributed to the data collection and manuscript preparation including revision process. C-GS supervised whole processes of experiments and manuscript preparation. All authors contributed to the article and approved the submitted version.

\section{REFERENCES}

Aufschnaiter, A., Kohler, V., Khalifa, S., Abd El-Wahed, A., Du, M., El-Seedi, H., et al. (2020). Apitoxin and Its Components against Cancer, Neurodegeneration and Rheumatoid Arthritis: Limitations and Possibilities. Toxins (Basel) 12 (2), E66. doi: 10.3390/toxins12020066

Blumenthal, K. G., Lai, K. H., Huang, M., Wallace, Z. S., Wickner, P. G., and Zhou, L. (2017). Adverse and Hypersensitivity Reactions to Prescription Nonsteroidal Anti-Inflammatory Agents in a Large Health Care System. J. Allergy Clin. Immunol. Pract. 5 (3), 737-743. doi: 10.1016/j.jaip.2016.12.006

Brockow, K., Romano, A., Blanca, M., Ring, J., Pichler, W., and Demoly, P. (2002). General considerations for skin test procedures in the diagnosis of drug hypersensitivity. Allergy 57 (1), 45-51. doi: 10.1046/j.0105-4538.2001. 00001.x-i8

Brown, S. G. (2004). Clinical features and severity grading of anaphylaxis. J. Allergy Clin. Immunol. 114 (2), 371-376. doi: 10.1016/j.jaci.2004.04.029

Demoly, P., Pichler, W., Pirmohamed, M., and Romano, A. (2008). Important questions in Allergy: 1 - drug allergy/hypersensitivity. Allergy 63 (5), 616-619. doi: 10.1111/j.1398-9995.2008.01693.x

Dispenza, M. C. (2019). Classification of hypersensitivity reactions. Allergy Asthma Proc. 40, 470-473. doi: 10.2500/aap.2019.40.4274

Giavina-Bianchi, P., Aun, M. V., and Kalil, J. (2018). Drug-induced anaphylaxis: is it an epidemic? Curr. Opin. Allergy Clin. Immunol. 18 (1), 59-65. doi: 10.1097/ ACI.0000000000000411

Golden, D. B. (2007). Insect sting anaphylaxis. Immunol. Allergy Clin. North Am. 27 (2), 261-272. doi: 10.1016/j.iac.2007.03.008

Gu, H. M., Kim, W. H., An, H. J., Kim, J. Y., Gwon, M. G., Han, S. M., et al. (2018). Therapeutic effects of bee venom on experimental atopic dermatitis. Mol. Med. Rep. 18 (4), 3711-3718. doi: 10.3892/mmr.2018.9398

Hartmann, A., Müllner, J., Meier, N., Hesekamp, H., van Meerbeeck, P., Habert, M. O., et al. (2016). Bee Venom for the Treatment of Parkinson Disease - A Randomized Controlled Clinical Trial. PloS One 11 (9), e0162937. doi: 10.1371/ journal

Hwang, Y., and Lee, B. (2000). Clinical study of anaphylaxis on bee venom acupuncture. J. Kor. Acup. Mox. Society 17 (4), 149-159.

Jarisch, R., Yman, L., Boltz, A., Sandor, I., and Janitsch, A. (1979). IgE antibodies to bee venom, phospholipase A, melittin and wasp venom. Clin. Allergy 9 (5), 535-341. doi: 10.1111/j.1365-2222.1979.tb02518.x

Jensen-Jarolim, E., and Untersmayr, E. (2008). Gender-medicine aspects in allergology. Allergy 63 (5), 610-615. doi: 10.1111/j.1398-9995.2008.01645.x

Jeong, Y. J., Shin, J. M., Bae, Y. S., Cho, H. J., Park, K. K., Choe, J. Y., et al. (2015). Melittin has a chondroprotective effect by inhibiting MMP-1 and MMP-8 expressions via blocking NF- $\mathrm{KB}$ and AP-1 signaling pathway in chondrocytes. Int. Immunopharmacol. 25 (2), 400-405. doi: 10.1016/j.intimp.2015.02.021

Jung, J. W., Jeon, E. J., Kim, J. W., Choi, J. C., Shin, J. W., Kim, J. Y., et al. (2012a). A Fatal Case of Intravascular Coagulation After Bee Sting Acupuncture. Allergy Asthma Immunol. Res. 4 (2), 107-109. doi: 10.4168/aair.2012.4.2.107

Jung, J. W., Kang, H. R., Kim, M. H., Lee, W., Min, K. U., Han, M. H., et al. (2012b). Immediate hypersensitivity reaction to gadolinium-based MR contrast media. Radiology 264 (2), 414-422. doi: 10.1148/radiol.12112025

\section{FUNDING}

This study was supported by the Ministry of Education, Science and Technology (NRF-2018R1A6A1A03025221) and the Ministry of Health and Welfare of South Korea (grant number: HI15C0006).

\section{SUPPLEMENTARY MATERIAL}

The Supplementary Material for this article can be found online at: https://www.frontiersin.org/articles/10.3389/fphar.2020. 545555/full\#supplementary-material

Kim, M. R., Shin, J. S., Lee, J. H., Lee, Y. J., Ahn, Y. J., Park, K. B., et al. (2016) Safety of Acupuncture and Pharmacopuncture in 80,523 Musculoskeletal Disorder Patients, A Retrospective Review of Internal Safety Inspection and Electronic Medical Records. Med. (Baltimore) 95 (18), e3635. doi: 10.1097/ MD.0000000000003635

Kwon, K. R., Kang, K. S., Lee, K. H., Lim, C. S., Jeong, H. S., and Kwon, H. Y. (2009). Clinical observation of anaphylaxis after treated with Sweet BV. J. Pharmacopuncture 12 (2), 85-90. doi: 10.3831/KPI.2009.12.2.085

Li, A., Wong, C. S., Wong, M. K., Lee, C. M., and Au Yeung, M. C. (2006). Acute adverse reactions to magnetic resonance contrast media - gadolinium chelates. Br. J. Radiol. 79 (941), 368-3671. doi: 10.1259/bjr/88469693

Liao, P. J., Mao, C. T., Chen, T. L., Deng, S. T., and Hsu, K. H. (2019). Factors associated with adverse drug reaction occurrence and prognosis, and their economic impacts in older inpatients in Taiwan: a nested case-control study. BMJ Open 9 (5), e026771. doi: 10.1136/bmjopen-2018-026771

Ma, L., Danoff, T. M., and Borish, L. (2014). Case fatality and population mortality associated with anaphylaxis in the United States. J. Allergy Clin. Immunol. 133 (3), 1075-1083. doi: 10.1016/j.jaci.2013.10.029

Memariani, H., Memariani, M., Shahidi-Dadras, M., Nasiri, S., Akhavan, M. M., and Moravvej, H. (2019). Melittin: from honeybees to superbugs. Appl. Microbiol. Biotechnol. 103 (8), 3265-3276. doi: 10.1007/s00253-019-09698-y

Merle, L., Laroche, M. L., Dantoine, T., and Charmes, J. P. (2005). Predicting and preventing adverse drug reactions in the very old. Drugs Aging 22 (5), 375-392. doi: 10.2165/00002512-200522050-00003

Mingarro, I., Pérez-Payá, E., Pinilla, C., Appel, J. R., Houghten, R. A., and Blondelle, S. E. (1995). Activation of bee venom phospholipase A2 through a peptide-enzyme complex. FEBS Lett. 372 (1), 131-134. doi: 10.1016/0014-5793 (95)00964-B

Mueller, H. L. (1966). Diagnosis and treatment of insect sensitivity. J. Asthma Res. 3 (4), 331-333. doi: 10.3109/02770906609106941

Nguyen, J. K., Fouts, M. M., Kotabe, S. E., and Lo, E. (2006). Polypharmacy as a risk factor for adverse drug reactions in geriatric nursing home residents. Am. J. Geriatr. Pharmacother. 4 (1), 36-41. doi: 10.1016/j.amjopharm.2006.03.002

Okano, M., Nishizaki, K., Satoskar, A. R., Yoshino, T., Masuda, Y., and Harn, D. A. Jr (1999). Involvement of carbohydrate on phospholipase A2, a bee-venom allergen, in vivo antigen-specific IgE synthesis in mice. Allergy 54 (8), 811-818. doi: 10.1034/ j.1398-9995.1999.00096.x

Onakpoya, I. J., Heneghan, C. J., and Aronson, J. K. (2019). Post-marketing withdrawal of 462 medicinal products because of adverse drug reactions: a systematic review of the world literature. BMC Med. 17 (1), 56. doi: 10.1186/ s12916-019-1294-9

Park, J. H., Yim, B. K., Lee, J. H., Lee, S., and Kim, T. H. (2015). Risk associated with bee venom therapy: a systematic review and meta-analysis. PloS One 10 (5), e0126971. doi: 10.1371/journal.pone.0126971

Pichler, W. J., and Hausmann, O. (2016). Classification of Drug Hypersensitivity into Allergic, p-i, and Pseudo-Allergic Forms. Int. Arch. Allergy Immunol. 171 (3-4), 166-179. doi: 10.1159/000453265

Rueff, F., Przybilla, B., Bilo, M. B., Muller, U., Scheipl, F., Aberer, W., et al. (2009). Predictors of severe systemic anaphylactic reactions in patients with Hymenoptera venom allergy: importance of baseline serum tryptase-a study 
of the European Academy of Allergology and Clinical Immunology Interest Group on Insect Venom Hypersensitivity. J. Allergy Clin. Immunol. 124 (5), 1047-1054. doi: 10.1016/j.jaci.2009.08.027

Seo, B. K., Han, K., Kwon, O., Jo, D. J., and Lee, J. H. (2017). Efficacy of Bee Venom Acupuncture for Chronic Low Back Pain: A Randomized, Double-Blinded, ShamControlled Trial. Toxins (Basel) 9 (11), E361. doi: 10.3390/toxins9110361

Simons, F. E., Ardusso, L. R., Bilò, M. B., El-Gamal, Y. M., Ledford, D. K., Ring, J., et al. (2011). World Allergy Organization. World Allergy organization anaphylaxis guidelines: summary. J. Allergy Clin. Immunol. 127 (3), 587-593. doi: 10.1016/j.jaci.2011.01.038

Turner, P. J., Jerschow, E., Umasunthar, T., Lin, R., Campbell, D. E., and Boyle, R. J. (2017). Fatal Anaphylaxis: Mortality Rate and Risk Factors. J. Allergy Clin. Immunol. Pract. 5 (5), 1169-1178. doi: 10.1016/j.jaip.2017.06.031

Vitte, J. (2015). Human mast cell tryptase in biology and medicine. Mol. Immunol. 63, 18-24. doi: 10.1016/j.molimm.2014.04.001

Wehbe, R., Frangieh, J., Rima, M., El Obeid, D., Sabatier, J. M., and Fajloun, Z. (2019). Bee Venom: Overview of Main Compounds and Bioactivities for Therapeutic Interests. Molecules 24 (16), E2997. doi: 10.3390/molecules 24162997
Wood, R. A., Camargo, C. A., Lieberman, P., Sampson, H. A., Schwartz, L. B., Zitt, M., et al. (2014). Anaphylaxis in America: the prevalence and characteristics of anaphylaxis in the United States. J. Allergy Clin. Immunol. 133 (2), 461- 467. doi: 10.1016/j.jaci.2013.08.016

Zhang, M., Holman, C. D., Price, S. D., Sanfilippo, F. M., Preen, D. B., and Bulsara, M. K. (2009). Comorbidity and repeat admission to hospital for adverse drug reactions in older adults: retrospective cohort study. BMJ 338, a2752. doi: 10.1136/bmj.a2752

Conflict of Interest: The authors declare that the research was conducted in the absence of any commercial or financial relationships that could be construed as a potential conflict of interest.

Copyright $\odot 2020$ Lee, Ahn, Kim, Oh, Park and Son. This is an open-access article distributed under the terms of the Creative Commons Attribution License (CC BY). The use, distribution or reproduction in other forums is permitted, provided the original author(s) and the copyright owner(s) are credited and that the original publication in this journal is cited, in accordance with accepted academic practice. No use, distribution or reproduction is permitted which does not comply with these terms. 